Virginia Commonwealth University

vCU Scholars Compass

Chemistry Publications

Dept. of Chemistry

2010

\title{
Spectrally tunable magnetic nanoparticles designed for distribution/recollection applications
}

Nicholas B. McDowall

Virginia Commonwealth University, United States Army Engineer Research and Development Center

James R. Wilkins

Virginia Commonwealth University, United States Army Engineer Research and Development Center

Kyler J. Carroll

Virginia Commonwealth University

See next page for additional authors

Follow this and additional works at: http://scholarscompass.vcu.edu/chem_pubs

Part of the Chemistry Commons

McDowall, N. B., Wilkins, J. R., \& Carroll, K. J., et al. Spectrally tunable magnetic nanoparticles designed for distribution/recollection applications. Journal of Applied Physics, 107, 09B327 (2010). Copyright (C) 2010 U.S. Government.

\section{Downloaded from}

http://scholarscompass.vcu.edu/chem_pubs/29

This Article is brought to you for free and open access by the Dept. of Chemistry at VCU Scholars Compass. It has been accepted for inclusion in Chemistry Publications by an authorized administrator of VCU Scholars Compass. For more information, please contact libcompass@vcu.edu. 
Authors

Nicholas B. McDowall, James R. Wilkins, Kyler J. Carroll, Jarrod D. Edwards, Jean D. Nelson, Everett E. Carpenter, and Garry P. Glaspell 


\title{
Spectrally tunable magnetic nanoparticles designed for distribution/recollection applications
}

\author{
Nicholas B. McDowall, ${ }^{1,2}$ James R. Wilkins, ${ }^{1,2}$ Kyler J. Carroll, ${ }^{1}$ Jarrod D. Edwards, ${ }^{2}$ \\ Jean D. Nelson, ${ }^{1,2}$ Everett E. Carpenter, ${ }^{2}$ and Garry P. Glaspell ${ }^{1,2, a)}$ \\ ${ }_{1}^{1}$ Department of Chemistry, Virginia Commonwealth University, Richmond, Virginia 23284, USA \\ ${ }^{2}$ United States Army Engineer Research and Development Center, Alexandria, Virginia 22315, USA
}

(Presented 20 January 2010; received 31 October 2009; accepted 1 December 2009; published online 17 May 2010)

\begin{abstract}
The comprehensive goal of this research is the synthesis and characterization of nanomaterials that are spectrally tunable in terms of their electromagnetic signal, are robust, magnetic (allowing their piloted movement), and have the potential to be functionalized for the detection of CBRNE threats. Various chemical methods were utilized for synthesis of magnetic (iron) and luminescent rare earth (RE) components, and their mixtures. Effects of integrating an iron core into RE luminescent lattices (excited by UV, emit in the VIS) were investigated. The determination of the optimum balances between magnetic and luminescent components such that the magnetism was maximized while maintaining acceptable fluorescence integrity will be discussed. The emphasis of this work is focused on developing a distributed sensor suitable for use in the terrestrial environment. The robust properties of using a RE luminescent shell would allow the particles to be resistant to photobleaching. Additionally the chemical stability of the RE shell would allow operation in a variety of $p \mathrm{H}$ conditions. The magnetic core will ultimately allow the distributed particles to be recollected. [doi:10.1063/1.3355900]
\end{abstract}

Multifunctional nanostructures have attracted significant interest. Specifically magnetic fluorescent nanoparticles serve as manipulative fluorescent probes with applications in nanoelectronic, biological, and catalytic applications. The simplest approach would be to decorate a magnetic nanoparticle with a fluorescent organic dye. However, due in part to the susceptibility that organic fluorophores may photobleach more elaborate measures have been taken. A variety of semiconductor coated magnetic particles have already been synthesized including $\mathrm{Fe}_{2} \mathrm{O}_{3}$ and $\mathrm{FePt}$ coated with $M \mathrm{~S}$ or $M \mathrm{Se}$ (where $\mathrm{M}=\mathrm{Cd}, \mathrm{Zn}, \mathrm{Hg}$ or $\mathrm{Pb}$ ). ${ }^{1-7}$ Both Liu and $\mathrm{Yu}$ have demonstrated that at room temperature the magnetic core semiconducting shell particles exhibit significant magnetic saturation and luminescence without the use of a spacer. ${ }^{8,9}$ This result is significant since a balance exists between the magnetic and fluorescent properties.

Rare earth (RE) nanoparticles are also being considered as an alternative to semiconductors for similar applications due in part to their long fluorescent lifetimes, high quantum yields, low photobleaching, high chemical stability, and are not prone to degradation over time. ${ }^{10-14}$

We have successfully generated bright orange, yellow, and red emitting FL-Mag-NPs, blue and green emitters were more challenging. Combining a series of RE dopants into a matrix produced a high degree of tunability (unique signatures), with luminescence covering the visible spectrum. The second objective of this research focuses on the feasibility of effective distribution, recollection and/or aggregation, and spectral analysis of our synthesized FL-Mag-NPs in variable environmental (aqueous and soil) conditions. We have dem-

\footnotetext{
${ }^{\text {a) }}$ Author to whom correspondence should be addressed. Electronic mail: garry.p.glaspell@us.army.mil.
}

onstrated the applicability of an external magnetic field (using a field portable electromagnet) as a technique for successful recollection of the Fluorescent-MagneticNanoparticles (FL-Mag-NPs) out of water or soil media, bringing them to the surface for more feasible remote interrogation.

The preparation of the aqueous ferrofluid comprised of iron nanoparticles was performed by a modified polyol process. ${ }^{15,16}$ The ferrofluid is then placed into a Parr bomb. To which $8.9 \mathrm{mmol}$ of $\mathrm{Y}\left(\mathrm{NO}_{3}\right)_{3}$ and $0.47 \mathrm{mmol}$ of $\mathrm{Eu}\left(\mathrm{NO}_{3}\right)_{3}$ were dissolved in $30 \mathrm{ml}$ of distilled water to which $7.5 \mathrm{mmol}$ of $\mathrm{Na}_{3} \mathrm{VO}_{4}$ was added. While stirring a white precipitate formed. The bomb was then sealed and placed in a conventional microwave for $1 \mathrm{~min}$. The precipitate was suspended in $40 \mathrm{ml}$ of distilled water, and $9.38 \mathrm{mmol}$ of 1-hydroxyethane-1,1-diphosphonic acid was added. The resulting solution was made basic by adding sodium hydroxide and the basic suspension was left to stir overnight. The resulting brown precipitate was magnetically separated, washed several times with DI water and vacuum dried. The as-prepared particles were characterized using transmission electron microscopy (TEM) (Joel JEM-1230 operated at 120 $\mathrm{kV}$ ) and $\mathrm{x}$-ray diffraction (XRD) (X'Pert Philips Materials Research diffractometer, with $\mathrm{Cu} K \alpha$ radiation). The compositions of the samples were determined using $\mathrm{X}$-ray fluorescence (XRF) (Horiba Jobin Yvon XGT-7000). The powderswere adhered to a glass slide using double-sided tape. The $\mathrm{x}$-ray tube voltage was set to $50.0 \mathrm{kV}$, the current was set to $1.0 \mathrm{~mA}$, and the sample diameter was $100 \mu \mathrm{m}$. Temperature and magnetic field variations in the magnetization $\chi$ of the as-prepared and treated samples were measured using a commercial superconducting quantum interference device magnetometer (Quantum Design). 


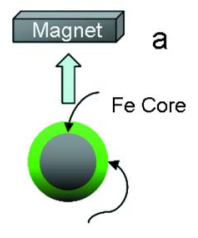

Luminescent Shell
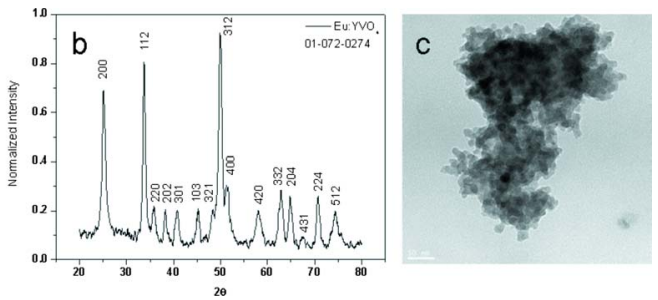

FIG. 1. (Color online) (a) Purposed structure of magnetic core luminescent shell particles, (b) XRD pattern of the as synthesized particles, and (c) TEM micrograph. The scale bar is $50 \mathrm{~nm}$.

To determine if the ability to recollect the particles once distributed, four different soil types were used to determine magnetic recollectability along a moisture gradient. These soils were characterized as being sand, loamy sand, clay mixture, and loam. Since each soil had different water potentials, the moisture variables used differed among soil types and approached saturation for each. Six moistures were evaluated for each soil that varied between soil types, including a dry variable. On the soil surface, $50 \mathrm{mg}$ of particles were distributed as evenly as possible and allowed to interact for $2 \mathrm{~h}$ in a sealed container. After this time the lid was removed and the samples were allowed to air dry for approximately $24 \mathrm{~h}$. Magnetic recollection was accomplished holding a samarium cobalt magnet not closer than $3 \mathrm{~mm}$ from the surface of the soil.

The synthesis and characterization of the ferrofluid has been described in detail in other publications. ${ }^{15,16}$ Briefly, the particles consist of an iron center surrounded by an iron oxide layer. The particles measure $\sim 10-15 \mathrm{~nm}$ in diameter and posses a magnetic saturation value of $\sim 92 \mathrm{emu} / \mathrm{g}$. The primary advantage of starting with a ferrofluid is that the magnetic particles are well isolated from each other and provide a good nucleation source for subsequent shell formation, as indicated in Fig. 1(a). Yttrium vanadate $\left(\mathrm{YVO}_{4}\right)$ was chosen as the host lattice for the luminescent shell. High luminescent quantum yield phosphors, in a variety of colors, can be produced by codoping the yttrium vanadate lattice with RE ions. In particular Eu doped $\mathrm{YVO}_{4}$ is an important commercial phosphor possessing a quantum yield of $\sim 70 \%$. It is often used in color televisions, the high pressure mercury lamp and as a scintillator in medical image detectors. ${ }^{17}$ It is also significant to note that $\mathrm{YVO}_{4}$ can be produced via a relatively mild hydrothermal route reducing the possibility that the magnetic core oxidizes. ${ }^{18}$ The XRD pattern of the resulting magnetic 5\% Eu doped $\mathrm{YVO}_{4}$ shell particles synthesized hydrothermally in the presence of ferrofluid is provided in Fig. 1(b). The diffraction pattern indicates that the $\mathrm{YVO}_{4}$ adopts a tetragonal crystal system and matches well with intensified charge coupled device database pattern 01072-0274. It is significant to note that no indication of Fe or $\mathrm{Fe}_{3} \mathrm{O}_{4}$ is evident in the diffraction pattern indicative that the magnetic core has a thick coating of $\mathrm{YVO}_{4}$. Also, the absence of a peak attribute to Eu is also a good indication that it is well dispersed in the lattice. The volume-weighted average crystalline size calculated from the XRD peak width using Scherrer's equation indicates that the crystallite size is $\sim 23 \mathrm{~nm}$. This is in good agreement with the TEM micrograph shown in Fig. 1(c). While the results from XRF con-
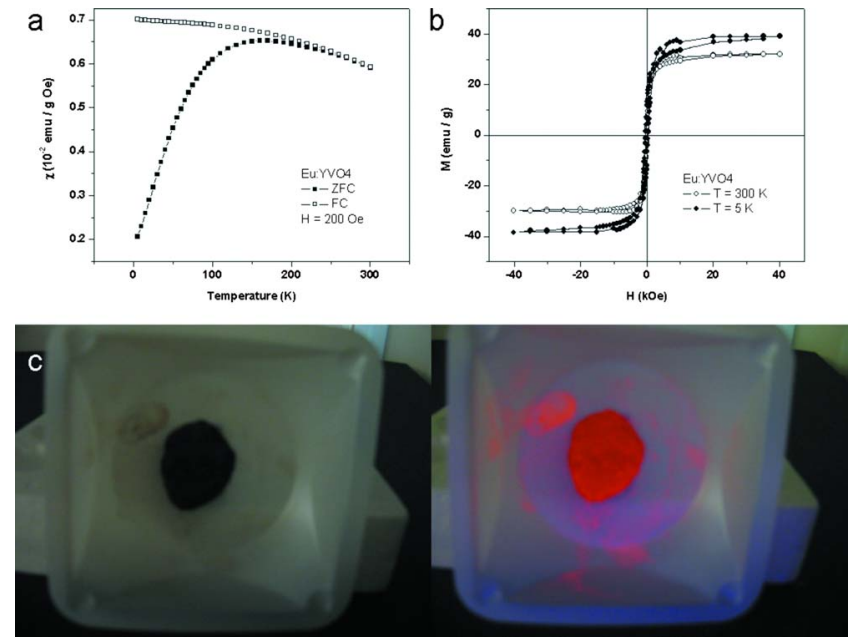

FIG. 2. (Color online) (a) Temperature dependence of the magnetic susceptibility $\chi$, (b) $\mathrm{M}$ vs $\mathrm{H}$ variations measured at 5 and $300 \mathrm{~K}$ for magnetic $5 \%$ $\mathrm{Eu}: \mathrm{YVO}_{4}$, and (c) photograph indicative of the magnetic and luminescent properties of the as-prepared magnetic luminescent nanoparticles.

firm that the Eu doping was 5.1\%, the percentage of Fe was lower than expected at $10.5 \%$. Since XRF is considered a surface technique this low value indicates that the magnetic core is well encased in a thick shell of $\mathrm{YVO}_{4}$.

The temperature variations of $\chi$ for both the field cooled (FC) and zero field cooled cases (ZFC) of the 5\% Eu doped $\mathrm{YVO}_{4}$ is shown in Fig. 2(a). It is evident from the curves that the sample displays an overall superparamagnetic character. However, the width of the blocking temperature for the ZFC case is suggestive of a wide distribution of particle sizes. The convergence of the temperature variation of $\chi$ above the blocking temperature for the FC and ZFC data is characteristic of interacting particles. This is indicative that some of the particles might have multiple magnetic centers resembling pomegranates rather than a true core shell nature. The results of measuring the hysteresis loops at 5 and $300 \mathrm{~K}$ are shown in Fig. 2(b). The highly symmetrical shape of the loops indicates that other mixed phases are not present in the sample. The magnetic saturation of the magnetic $5 \% \mathrm{Eu}$ doped $\mathrm{YVO}_{4}$ was determined to be $\sim 41.1 \mathrm{emu} / \mathrm{g}$ significantly less than the $92 \mathrm{emu} / \mathrm{g}$ reported for the particles making up the ferrofluid. This lower value is attributed to the diamagnetic contribution of the $\mathrm{YVO}_{4}$ lattice. While somewhat diminished the overall magnetic responsivity is significant enough to allow the particles to be piloted in the presence of a magnetic field as shown in Fig. 2(c).

The luminescent spectra of magnetic 5\% Eu doped $\mathrm{YVO}_{4}$ is shown in Fig. 3(a). It has been well documented that strong luminescence occurs from efficient energy transfer from the $\mathrm{VO}_{4}^{3-}$ group to $\mathrm{Eu}^{3+}$, specifically attributed to the charge transfer from the oxygen ligands to the central vanadium atom, and this transition is known to occur at $\sim 300 \mathrm{~nm}$. Thus, we have chosen $290 \mathrm{~nm}$ as the excitation wavelength. ${ }^{19}$ It has also been previously determined that the quantum yield shows a maximum at a doping level of $\sim 5 \mathrm{~mol} \%$ and slowly decreases as the concentration is increased further. ${ }^{18}$ Concentration quenching is observed if the mean distance between neighboring Eu ions decrease below a fixed value. The characteristic luminescence spectra shown 

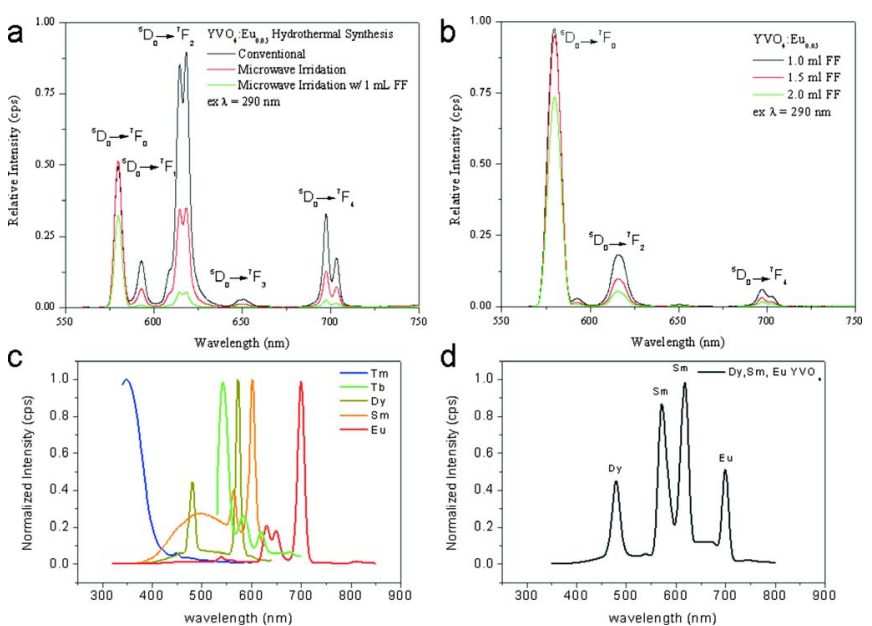

FIG. 3. (Color online) Emission spectra of (a) conventional and magnetic core luminescent nanoparticles prepared hydrothermally, (b) varying amounts of ferrofluid, (c) by varying the RE dopant, and (d) unique signatures can be created by combining various dopants.

in Fig. 3(a) is attributed to the Eu ion substituting for an yttrium ion in the lattice. This site has $\mathrm{D}_{2 \mathrm{~d}}$ symmetry which gives rise to crystal field splitting observed in the emission spectra. ${ }^{18}$ The intensity of the transitions between different $\mathrm{J}$ levels depends on the symmetry of the environment the $\mathrm{Eu}$ ion occupies. For the conventional Eu doped $\mathrm{YVO}_{4}$ sample, no magnetic core, the ${ }^{5} \mathrm{D}_{0}-{ }^{7} \mathrm{~F}_{2}$ forced electric dipole transition is the strongest. However, when the reaction is run in the presence of ferrofluid the ${ }^{5} \mathrm{D}_{0}-{ }^{7} \mathrm{~F}_{1}$ magnetic dipole transition is the strongest. Literature shows that the ${ }^{5} \mathrm{D}_{0}-{ }^{7} \mathrm{~F}_{2}$ transition is only possible when $\mathrm{Eu}^{3+}$ is located at a site of noninversion symmetry while the ${ }^{5} \mathrm{D}_{0}-{ }^{7} \mathrm{~F}_{1}$ is possible at a site with centrosymmetry. ${ }^{20}$ It is believed that this distortion from the inversion symmetry is attributed to the magnetic core. As indicated in Fig. 3(b) increasing the amount of ferrofluid present in the reaction is inversely proportional to the intensity of the observed emission. We have also shown that incorporating various $\mathrm{Ln}$ ions in the place of $\mathrm{Eu}$ it is possible to generate a variety of colors. It is significant to note that the doping levels of the various $\mathrm{Ln}$ ions were kept at 5\%. The primary emission peak of Sm occurs at $602 \mathrm{~nm}$. This peak arises from the ${ }^{4} \mathrm{G}_{5 / 2}-{ }^{6} \mathrm{H}_{7 / 2}$ transition and gives rise to an orange emission. A secondary peak at $564 \mathrm{~nm}$ is attributed to the ${ }^{4} \mathrm{G}_{5 / 2}-{ }^{6} \mathrm{H}_{5 / 2}$ transition. Doping with Dy produces a yellow emission arising from two transitions specifically ${ }^{4} \mathrm{~F}_{9 / 2}-{ }^{6} \mathrm{H}_{15 / 2}$ and ${ }^{4} \mathrm{~F}_{9 / 2}-{ }^{6} \mathrm{H}_{13 / 2}$ occurring at $573 \mathrm{~nm}$ and 482 $\mathrm{nm}$, respectively. Green emission is possible by doping with $\mathrm{Tb}$. The primary emission from $\mathrm{Tb}$ occurs at $543 \mathrm{~nm}$ and is due to the ${ }^{5} \mathrm{D}_{4}-{ }^{7} \mathrm{~F}_{5}$ transition. Finally to obtain a blue emission, we attempted to dope the Tm within the lattice. A peak at $349 \mathrm{~nm}$ was observed this could be attributed to the ${ }^{1} \mathrm{D}_{2}-{ }^{3} \mathrm{H}_{6}$ transition. However, the low intensity peak at 460 $\mathrm{nm}$ arising from the ${ }^{1} \mathrm{D}_{2}-{ }^{3} \mathrm{~F}_{4}$ transition and the peak width of the $349 \mathrm{~nm}$ peak would indicate that the emission is coming from the lattice and not necessarily the $\mathrm{Tm}$. We have also shown in Fig. 3(d) that codoping with multiple ions leads to unique emission spectra.

Finally, in order to test the robustness of these particles in an environmental recollection scenario, their behavior was observed on both moist and dry soils. Four different soil types were used that varied in $p \mathrm{H}$, water potential, and composition (sand, loamy sand, loam, and clay mixture). The moisture variables for each soil were determined by their water potential and approached saturation for each different soil type. While no correlations were found between magnetic recollectability and $p \mathrm{H}$, moisture, and composition were found to affect recollection. The particles were found to readily adsorb water from the soil and adhered to the soil surface, forming a crust that clung to the soil underneath it. Magnetic recollection was near $100 \%$ on all dry soils, however, on moist soil recollection was observed to depend more on the soil density, moisture, and the aggregation of the particles. Since the particles adhered to the moist soil below, recollection from denser soils (sand and loamy sand) was difficult. While recollection was more successful on lower density soils (loam and clay mixture), the recollected material was laden with soil. Moisture was found to impede recollection as it increased but also depended on how aggregated the particles were on the soil surface.

In conclusion, we have demonstrated the synthesis of multifunctional nanoparticles that are both luminescent and magnetic at room temperature. By varying the RE dopant, it is possible to vary the emission wavelength or create unique signatures by combining them.

${ }^{1}$ P. D. Cozzoli, T. Pellegrino, and L. Manna, Chem. Soc. Rev. 35, 1195 (2006).

${ }^{2}$ V. Salgueirio-Maceira, M. A. Crrea-Duarte, M. Spasova, L. M. Liz-Marzn, and M. Farle, Adv. Funct. Mater. 16, 509 (2008).

${ }^{3}$ H. W. Gu, R. K. Zheng, H. Liu, X. X. Zhang, and B. Xu, Small 1, 044308 (2005).

${ }^{4}$ J. H. Gao, B. Zhang, Y. Gao, Y. Pan, X. X. Zhang, and B. Xu, J. Am. Chem. Soc. 129, 11928 (2007).

${ }^{5}$ J. Gao, W. Zhang, P. Huang, B. Zhang, X. Zhang, and B. Xu, J. Am. Chem. Soc. 130, 3710 (2008).

${ }^{6}$ W. Shi, H. Zeng, Y. Sahoo, T. Y. Ohulchanskyy, Y. Ding, Z. L. Wang, M. Swihart, and P. N. Pradad, Nano Lett. 6, 875 (2006).

${ }^{7}$ S. T. Selvan, P. K. Patra, C. Y. Ang, and J. Y. Ying, Angew. Chem., Int. Ed. 46, 875 (2007).

${ }^{8}$ Z. Liu, Q. Hu, X. Zhang, Z. Feng, and Q. Wang, J. Phys. Chem. C 112, 334302 (2008).

${ }^{9}$ X. Yu, J. Wan, Y. Shan, K. Chen, and X. Han, Chem. Mater. 21, 4892 (2009).

${ }^{10}$ A. Quarta, R. Di Corato, L. Manna, S. Argentiere, R. Cingolani, G. Barbarella, and T. J. Pellegrino, J. Am. Chem. Soc. 130, 324339 (2008).

${ }^{11}$ W. C. W. Chan and S. M. Nie, Science 281, 134303 (1998).

${ }^{12}$ L. Y. Wang and Y. D. Li, Chem. Mater. 19, 727 (2007).

${ }^{13}$ S. Sivakumar, F. van Veggel, and M. Raudsepp, J. Am. Chem. Soc. 127, 366116 (2005).

${ }^{14}$ H. Yu, M. Chen, P. M. Rice, S. X. Wang, R. L. White, and S. H. Sun, Nano Lett. 5, 379 (2005).

${ }^{15}$ K. J. Carroll, M. D. Shultz, P. P. Fatouros, and E. E. Carpenter, J. Appl. Phys. 107 (in press).

${ }^{16}$ K. J. Carroll, S. Calvin, T. F. Ekiert, K. M. Unruh, and E. E. Carpenter, Chem. Mater. (2010).

${ }^{17}$ Z. Hou, P. Yang, C. Li, L. Wang, H. Lian, Z. Quan, and J. Lin, Chem. Mater. 20, 6686 (2008).

${ }^{18}$ K. Riwotzki and M. Hasse, J. Phys. Chem. B 102, 10129 (1998).

${ }^{19}$ G. Wang, W. Qin, J. Zhang, J. Zhang, Y. Wang, C. Cao, L. Wang, G. Wei, P. Zhu, and R. Kim, J. Phys. Chem. C 112, 12161 (2008).

${ }^{20} \mathrm{~W}$. Li and J. Lee, J. Phys. Chem. C 112, 11679 (2008). 